\title{
Growth, structural, optical, thermal and mechanical properties of ammonium pentaborate single crystal
}

\author{
T. Balakrishnan ${ }^{\text {a }}$, G. Bhagavannarayana ${ }^{\mathrm{b}}$, K. Ramamurthi ${ }^{\mathrm{a}, *}$ \\ ${ }^{a}$ Crystal Growth and Thin Film Laboratory, School of Physics, Bharathidasan \\ University, Tiruchirappalli, Tamil Nadu 620024, India \\ ${ }^{\mathrm{b}}$ Materials Characterization Division, National Physical Laboratory, New Delhi 110012, India
}

Received 1 December 2007; accepted 7 January 2008

\begin{abstract}
Nonlinear optical single crystals of ammonium pentaborate (APB) were grown by the slow cooling method from aqueous solution. Grown crystal was characterized by powder X-ray diffraction (PXRD) and FT-IR spectral analysis. Perfection of the grown crystal was evaluated by high-resolution X-ray diffractometry (HRXRD). The effect of nylon threading on the perfection of the grown bigger crystal was also studied by HRXRD. The range and percentage of optical transmission was ascertained by recording UV-vis-NIR spectrum. Thermal properties were investigated by TG-DTA and DSC analyses. Its mechanical hardness was estimated by Vickers microhardness tester.
\end{abstract}

(C) 2008 Elsevier B.V. All rights reserved.

PACS: $81.10 . \mathrm{Dn} ;$ 81.70.Pg; $42.70 . \mathrm{Nq}$

Keywords: Crystal growth; Powder X-ray diffraction; High-resolution X-ray diffraction; Thermal properties; Mechanical properties; Nonlinear optical properties

\section{Introduction}

Boron and its compounds have wide range of applications in industry [1]. The boron atom usually coordinates with either three/four oxygen or fluorine atoms forming $\left[\mathrm{BO}_{3}\right]^{3-}$ or $\left[\mathrm{BO}_{4}\right]^{5-}$ or $\left[\mathrm{BF}_{4}\right]^{-}$groups. Accordingly, the electronic orbitals are hybridized to a planar $\mathrm{sp}^{2}$ or a three dimensional $\mathrm{sp}^{3}$ structure. The various structural possibilities for the boron atoms are one of the reasons for the attractive versatility of borates in the field of nonlinear optics. Ammonium pentaborate (APB), an alkaline salt, is a product resulting from the controlled reaction of ammonia, water and boric acid. It is used in the preparation of both wet and dry high-quality electrolytic capacitors. This material is also used as corrosion inhibitor. Since the APB is an excellent solvent for metallic oxides at high temperatures, it is used in the preparation of special welding, soldering and brazing fluxes for stainless steel or nonferrous metals. The piezoelectric and dielectric properties of APB and its isomorph potassium pentaborate have been determined by Cook and Jaffe [2]. The

\footnotetext{
* Corresponding author. Tel.: +91 4312407057.

E-mail addresses: balaphy@ rediffmail.com (T. Balakrishnan), krmurthin@yahoo.co.in (K. Ramamurthi).
}

elastic constants [3] and optical behaviour of ammonium pentaborate under linear and hydrostatic stresses [4] were reported. Solans et al. [5] have reported the morphological studies of $\alpha$ and $\beta$-phases of APB. In the present investigation, the growth, structural, mechanical, and thermal properties of $\alpha$-phase APB are reported.

\section{Experimental}

\subsection{Solubility and metastable zonewidth}

To grow bulk crystals from solution, selection of suitable solvent is an important task. The size of a crystal depends on the amount of material available in the solution which in turn is decided by the solubility of the material in that solvent. Test on various solvents such as ethanol, methanol and distilled water reveals from the transparency and morphology of the grown crystals that water is a more suitable solvent. Hence, in this work, double distilled water is used as the solvent. Solubility of APB was determined in double distilled water at five different temperatures viz., $30,35,40,45$ and $50^{\circ} \mathrm{C}$. Solubility at a particular temperature was determined by dissolving the APB salt in $100 \mathrm{ml}$ of double distilled water taken in an airtight container 


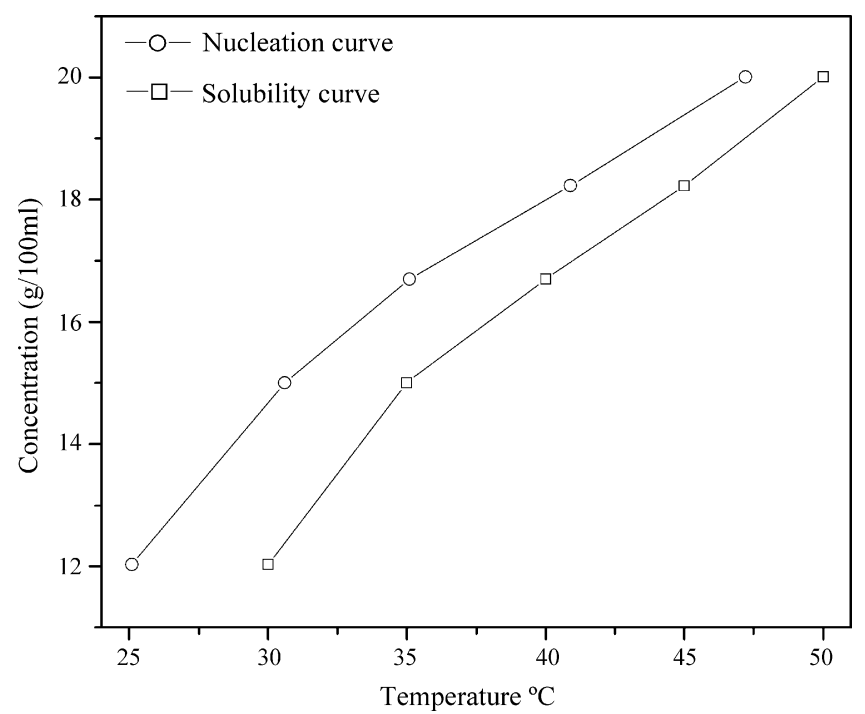

Fig. 1. Solubility curve and metastable zonewidth of APB.

maintained at the same temperature with continuous stirring. After attaining the saturation, the equilibrium concentration of the solute was estimated gravimetrically. The same procedure was repeated to estimate the solubility at different temperatures. Presently determined solubility data were utilized for the determination of metastable zonewidth. The nucleation studies were carried out in a constant temperature bath having an accuracy of $\pm 0.01{ }^{\circ} \mathrm{C}$. A constant volume of $100 \mathrm{ml}$ of salt solution was used in all the experiments. The solution was preheated to $5{ }^{\circ} \mathrm{C}$ above the saturation temperature for homogenization and left at the superheated temperature for about an hour before cooling. Metastable zonewidth of APB was estimated using the conventional polythermal method [6]. The variation of solubility along with metastable zonewidth for different temperatures of APB solution is shown in Fig. 1.

\subsection{Crystal growth}

Commercially available APB was twice recrystallized and used. According to the measured solubility data $33.4 \mathrm{~g}$ of APB was dissolved in $200 \mathrm{ml}$ of double distilled water at $40{ }^{\circ} \mathrm{C}$. The

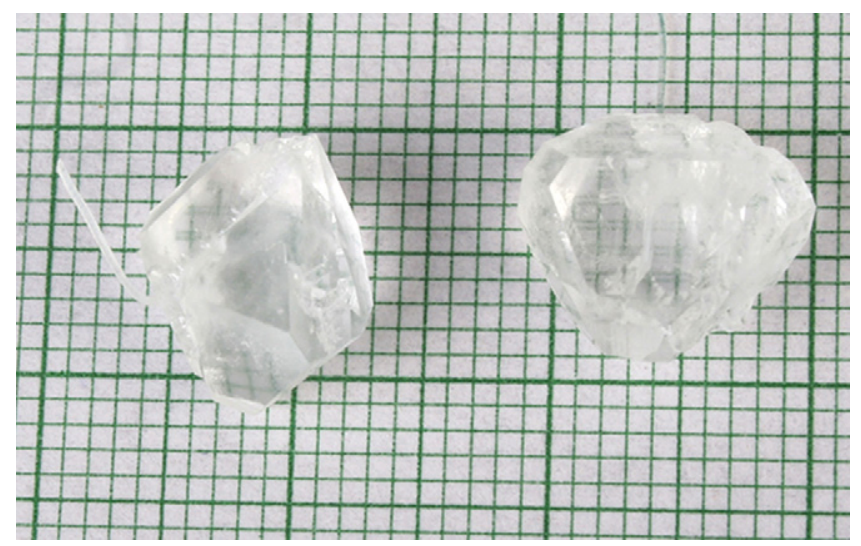

Fig. 2. As-grown crystal of APB.
Table 1

Unit cell parameters of APB

\begin{tabular}{lcc}
\hline & Present work & Reported values [5] \\
\hline$a(\AA)$ & $7.189(5)$ & 7.115 \\
$b(\AA)$ & $11.308(5)$ & 11.301 \\
$c(\AA)$ & $7.217(6)$ & 7.183 \\
$\beta$ & $100.12(7)^{\circ}$ & $99.92^{\circ}$ \\
Volume $\left(\AA^{3}\right)$ & $578(2)$ & $577(5)$ \\
\hline
\end{tabular}

solution was filtered using Whatman filter paper. The solution was taken in a beaker and maintained at this temperature in a constant temperature bath having an accuracy of $\pm 0.01^{\circ} \mathrm{C}$. Good transparent crystals were obtained by slow evaporation method at room temperature. Large size crystals were grown by suspending the seed crystal obtained from slow evaporation method at room temperature by a nylon thread. Crystal growth process was initiated in the saturated solution at $40^{\circ} \mathrm{C}$. Following the slow cooling method the temperature of the bath was reduced from $40{ }^{\circ} \mathrm{C}$ at a rate of $0.1{ }^{\circ} \mathrm{C}$ per day. The single crystal of size $11 \mathrm{~mm} \times 10 \mathrm{~mm} \times 6 \mathrm{~mm}$ was harvested after a growth period of 15 days and is shown in Fig. 2.

\section{Results and discussion}

\subsection{XRD analysis}

The grown crystal was subjected to single crystal X-ray diffraction study at room temperature using BRUKER NONIUS $\mathrm{CAD} 4$ single crystal X-ray diffractometer with $\mathrm{Cu} \mathrm{K} \alpha$ radiation $(\lambda=1.5405 \AA)$. At room temperature, APB crystal belongs to monoclinic system and the cell parameters are presented in Table 1 which are well matched with the reported values [5].

Powder X-ray diffraction study was carried out employing SEIFERT JSO DEB YEFLEX (Model 2002) diffractometer with $\mathrm{Cu} \mathrm{K} \alpha(\lambda=1.5405 \AA)$ radiation. The powdered sample was scanned over the $2 \theta$ range of $10-80^{\circ}$ at a rate of $1^{\circ} \mathrm{min}^{-1}$. From the X-ray diffraction data the various planes of reflec-

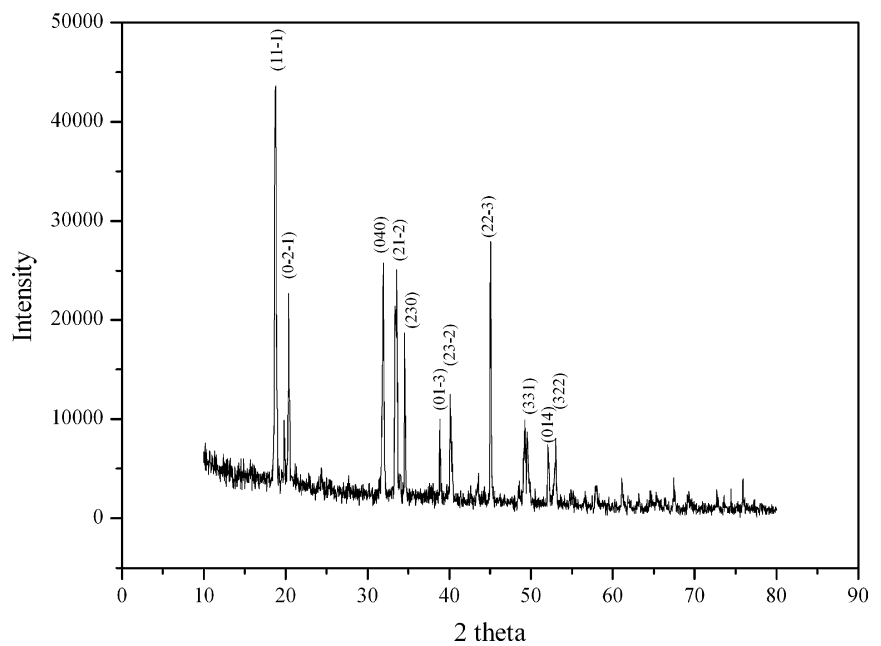

Fig. 3. Powder X-ray diffraction of APB. 
tions were indexed using the software AUTOX 93. The indexed $\mathrm{X}$-ray diffraction pattern is given in Fig. 3 .

\subsection{High resolution X-ray diffractometry (HRXRD)}

To reveal the crystalline perfection of the grown crystal and to study the influence of the nylon threading on the perfection of the grown bulk crystal, a multicrystal X-ray diffractometer (MCD) developed at NPL [7] has been utilized to record high-resolution diffraction curves $(\mathrm{DCs})$. In this system a fine focus $(0.4 \times 8 \mathrm{~mm}$; $2 \mathrm{~kW}$ Mo) X-ray source energized by a well-stabilized Philips $\mathrm{X}$-ray generator (PW 1743) was employed. The well-collimated and monochromated $\mathrm{MoK} \alpha_{1}$ beam obtained from the three monochromator Si crystals set in dispersive $(+,-,-)$ configuration has been used as the exploring X-ray beam. This arrangement improves the spectral purity $\left(\Delta \lambda / \lambda \ll 10^{-5}\right)$ of the Mo $\mathrm{K} \alpha_{1}$ beam. The divergence of the exploring beam in the horizontal plane (plane of diffraction) was estimated to be « $3^{\prime \prime}$. The specimen crystal is aligned in the $(+,-,-,+)$ configuration. Due to dispersive configuration, though the lattice constant of the monochromator crystal(s) and the specimen are different, the unwanted dispersion broadening in the diffraction curve of the specimen crystal is insignificant. The specimen can be rotated about a vertical axis, which is perpendicular to the plane of diffraction, with minimum angular interval of $0.5^{\prime \prime}$. The diffracted intensity is measured by using a scintillation counter. The rocking or diffraction curves were recorded by changing the glancing angle (angle between the incident X-ray beam and the surface of the specimen) around the Bragg diffraction peak position $\theta_{\mathrm{B}}$ (taken zero as reference point) starting from a suitable arbitrary glancing angle $(\theta)$. The detector was kept at the same angular position $2 \theta_{\mathrm{B}}$ with wide opening for its slit, the so-called $\omega$ scan. For all the specimens of the present study, the X-ray power, size of the beam, configuration of the diffractometer were kept constant. Before recording the diffraction curve, to remove the non-crystallized solute atoms remaining on the surface of the crystal and also to ensure the surface planarity, the specimens were first lapped and chemically etched in a non-preferential etchent of water and acetone mixture in 1:2 volume ratio.

Curve (a) in Fig. 4 shows the DC for APB specimen recorded for $\left(\begin{array}{lll}1 & 1 & \overline{1}\end{array}\right)$ diffracting planes in symmetrical Bragg geometry. As mentioned in the growth procedure, the bulk crystal of this specimen was grown by hanging a seed crystal in the solution using a nylon thread. The DC was recorded for the specimen of the grown crystal cut from a region, which is $4 \mathrm{~mm}$ away from the position of the thread. As seen in the figure, the curve does not contain a single peak. The solid line, which follows well with the experimental points (filled circles), is the convoluted curve of three peaks using the Lorentzian fit. The two additional peaks, which are $162^{\prime \prime}$ and $232^{\prime \prime}$ away from the main peak correspond to two internal structural low angle boundaries (tilt angle $>1^{\prime}$ but less than an arc degree) whose tilt angles (misorientation angle between the two crystalline regions on both sides of the structural grain boundary) are $162^{\prime \prime}$ and $70^{\prime \prime}$, respectively. The full width at half maximum (FWHM) of the main peak and the low angle boundaries are respectively $35^{\prime \prime}, 105^{\prime \prime}$ and $40^{\prime \prime}$. Though the specimen contains low angle boundaries, the relatively low angular

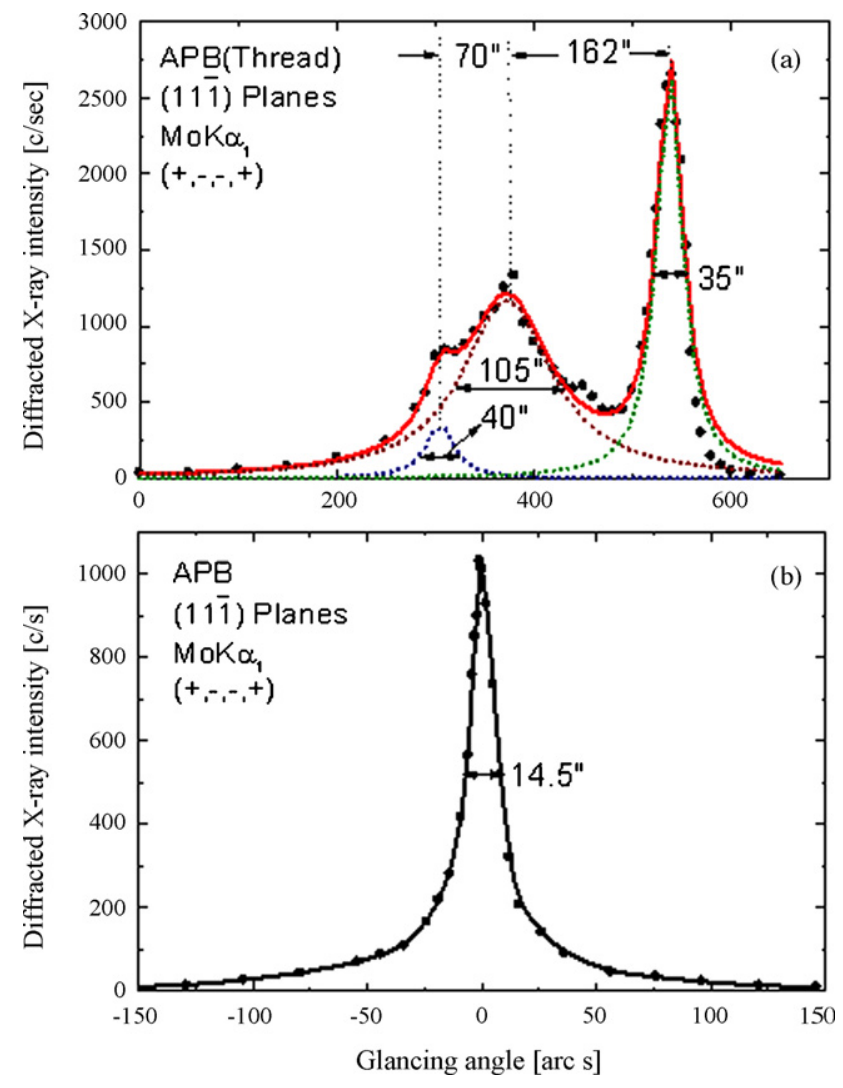

Fig. 4. Diffraction curves recorded for APB single crystals for (1 $11 \overline{1})$ diffraction planes: (a) for a specimen grown by hanging a seed crystal using nylon thread and (b) for a seed crystal.

spread of around $400^{\prime \prime}$ of the diffraction curve shows that the crystalline perfection is reasonably good. The main reason for the presence of low angle boundaries is due to the nylon thread used to grow the bulk crystal. Due to the foreign material in between the crystalline matrix, the crystal quality deteriorates and the regions close to the thread develop internal structural grain boundaries and extend to considerable length [7]. It may be mentioned here that such low angle boundaries could be detected with well-resolved peaks in the diffraction curve only because of the high-resolution of the multicrystal X-ray diffractometer used in the present studies.

Curve (b) in Fig. 4 is the DC recorded for the as-grown seed crystal directly obtained from the solution. As seen in the figure, in contrast with curve (a), the DC is quite sharp without any satellite peaks showing the absence of internal structural grain boundaries. The full width at half maximum of the diffraction curve is $14.5^{\prime \prime}$, which is close to that expected from the plane wave dynamical theory of X-ray diffraction [8]. The single sharp diffraction curve with low FWHM indicates that the crystalline perfection is very good. The specimen is a nearly perfect single crystal without having any internal structural grain boundaries and dislocations. However, the relatively high scattered intensity than that of a theoretically expected curve, along the tails on both sides of the peak indicates point defects and their aggregates $[8,9]$, which are in general inescapable due to thermodynamical considerations and unavoidable impurities. 


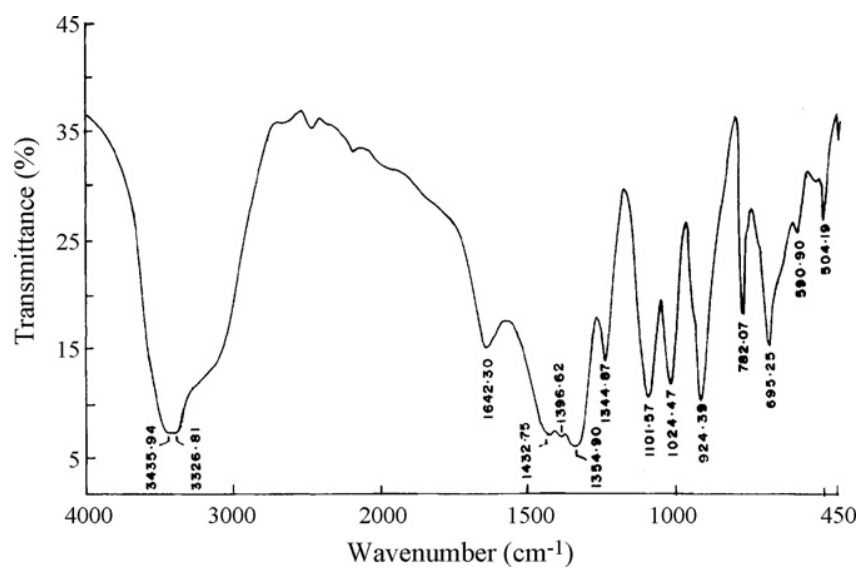

Fig. 5. FT-IR spectrum of APB.

\subsection{FT-IR studies}

The Fourier transform infrared spectrum of APB crystal was recorded on PerkinElmer FT-IR spectrophotometer using $\mathrm{KBr}$ pellet technique at $300 \mathrm{~K}$ in the range of $450-4000 \mathrm{~cm}^{-1}$. The FT-IR spectrum of APB is presented in Fig. 5 and vibrational frequencies with their assignments are summarized in Table 2. The vibrational frequencies of APB are also compared with the corresponding vibrational frequencies of its isomorph, potassium pentaborate $(\mathrm{KPB})$. The very strong bands absorbed at $3435 \mathrm{~cm}^{-1}$ and $3326 \mathrm{~cm}^{-1}$ are due to $\mathrm{OH}$ asymmetric and symmetric stretching vibrations, respectively. The B-O vibrations of borate crystal have their absorption bands in the frequency region $782-1432 \mathrm{~cm}^{-1}$. The band observed at $1642 \mathrm{~cm}^{-1}$ is assigned to $\mathrm{NH}_{4}$ asymmetric bending vibrations. The very strong peak at $1024 \mathrm{~cm}^{-1}$ is attributed to B-O terminal symmetric stretching vibration. The $\mathrm{B}-\mathrm{O}$ terminal asymmetric stretching vibration is observed at $1432 \mathrm{~cm}^{-1}[10]$.

\section{4. $U V-v i s-N I R$ spectrum}

The optical absorption spectrum of APB crystal was recorded in the range 200-1500 nm using Varian Cary 5E UV-vis-NIR spectrophotometer. Fig. 6 shows the UV-vis-NIR spectrum

Table 2

Vibrational band assignments of APB

\begin{tabular}{lll}
\hline KPB [10] & APB & Band assignments \\
\hline 3445 & 3435 & $(\mathrm{O}-\mathrm{H})$ asymmetric stretching \\
- & 3326 & $(\mathrm{O}-\mathrm{H})$ symmetric stretching \\
- & 1642 & $\mathrm{NH}_{4}$ asymmetric bending, $(\mathrm{O}-\mathrm{H})$ bending \\
1438 & 1432 & $\mathrm{~B}-\mathrm{O}$ termminal asymmetric stretching \\
- & 1396 & $\mathrm{NH}_{4}$ symmetric bending \\
1356 & 1354 & $\mathrm{~B}-\mathrm{O}$ asymmetric stretching \\
1251 & 1244 & $\mathrm{CH}_{2}$ torsion \\
1103 & 1101 & $\mathrm{~B}-\mathrm{O}$ terminal asymmetric stretching \\
1027 & 1024 & $\mathrm{~B}-\mathrm{O}$ terminal symmetric stretching \\
923 & 924 & $\mathrm{~B}-\mathrm{O}$ ring stretching \\
784 & 782 & $\mathrm{~B}-\mathrm{O}$ ring stretching \\
695 & 695 & $\mathrm{O}-\mathrm{B}-\mathrm{O}$ ring asymmetric bending \\
591 & 590 & $\mathrm{O}-\mathrm{B}-\mathrm{O}$ terminal bending \\
509 & 504 & $\mathrm{O}-\mathrm{B}-\mathrm{O}$ ring bending \\
\hline
\end{tabular}

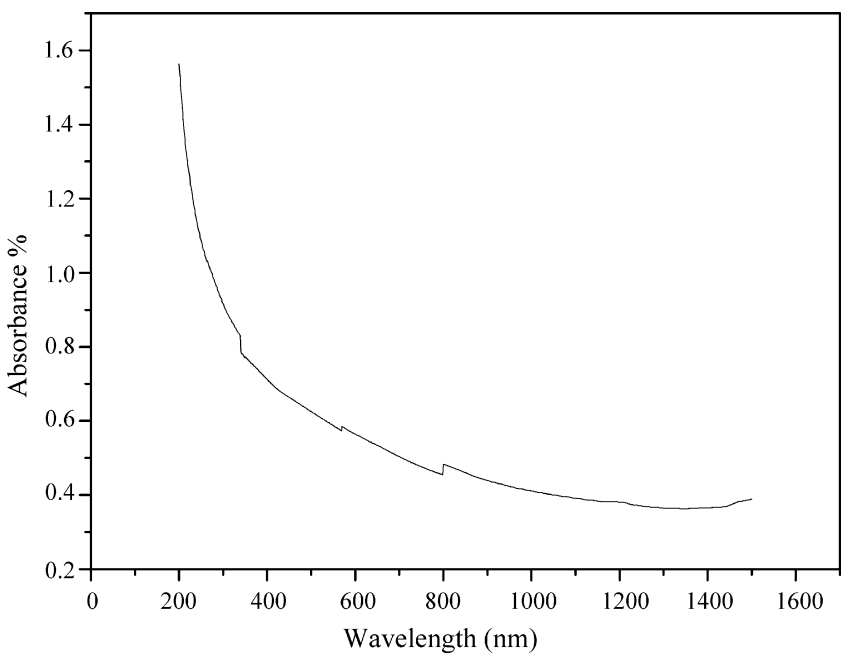

Fig. 6. UV-vis-NIR absorbance spectra of APB.

recorded with highly transparent single crystal of APB of thickness $3 \mathrm{~mm}$. It is observed that the lower cut off of APB crystal is at $240 \mathrm{~nm}$ and the crystal is found to be transparent in the region of $250-1500 \mathrm{~nm}$ which is an essential parameter for frequency doubling process.

\subsection{Thermal analysis}

Thermogravimetric analysis (TGA) and Differential Thermal Analysis (DTA) are very important characteristic techniques to identify the thermal stability of the grown crystal. TG/DTG and DTA curves were recorded for the APB crystal using PerkinElmer thermal analyzer in the range of temperature from 28 and $1200{ }^{\circ} \mathrm{C}$ at a heating rate of $20^{\circ} \mathrm{C} / \mathrm{min}$ in nitrogen atmosphere (Fig. 7). A ceramic crucible was used for heating the sample. The initial mass of the material subjected to analysis was $10.935 \mathrm{mg}$. Three weight loss steps were observed from the TGA curve. The material was stable up to $165.87^{\circ} \mathrm{C}$ and then weight loss takes place. As seen in the reaction steps the thermal decomposition of APB [11] takes place in three steps: dehydration, decomposition and deammination (removal of ammonia). In the first step of decomposition three water molecules were removed. The second step of weight loss takes place between the temperature $288.01^{\circ} \mathrm{C}$ and $333^{\circ} \mathrm{C}$. In the second stage of weight loss another two water molecules takes place. These two water molecules are difficult to remove during dehydration and can only be removed by decomposition. Third step of decomposition is observed between the temperature $416.22^{\circ} \mathrm{C}$ and $445^{\circ} \mathrm{C}$. During this stage of decomposition one ammonia molecule is removed. The DTA curve clearly follows the TG curve except a very small defused peak appears at $130{ }^{\circ} \mathrm{C}$ and can be neglected. Sharp and well resolved peak is observed at $184.92^{\circ} \mathrm{C}$ as the second endotherm which is due to the decomposition of another two molecule. Third endothermic peak is observed at $311.88^{\circ} \mathrm{C}$ and corresponds to the loss of two water molecules present in the crystal lattice. The fourth endothermic peak is observed at $440.52^{\circ} \mathrm{C}$ which is related to the removal of ammonia molecule. 


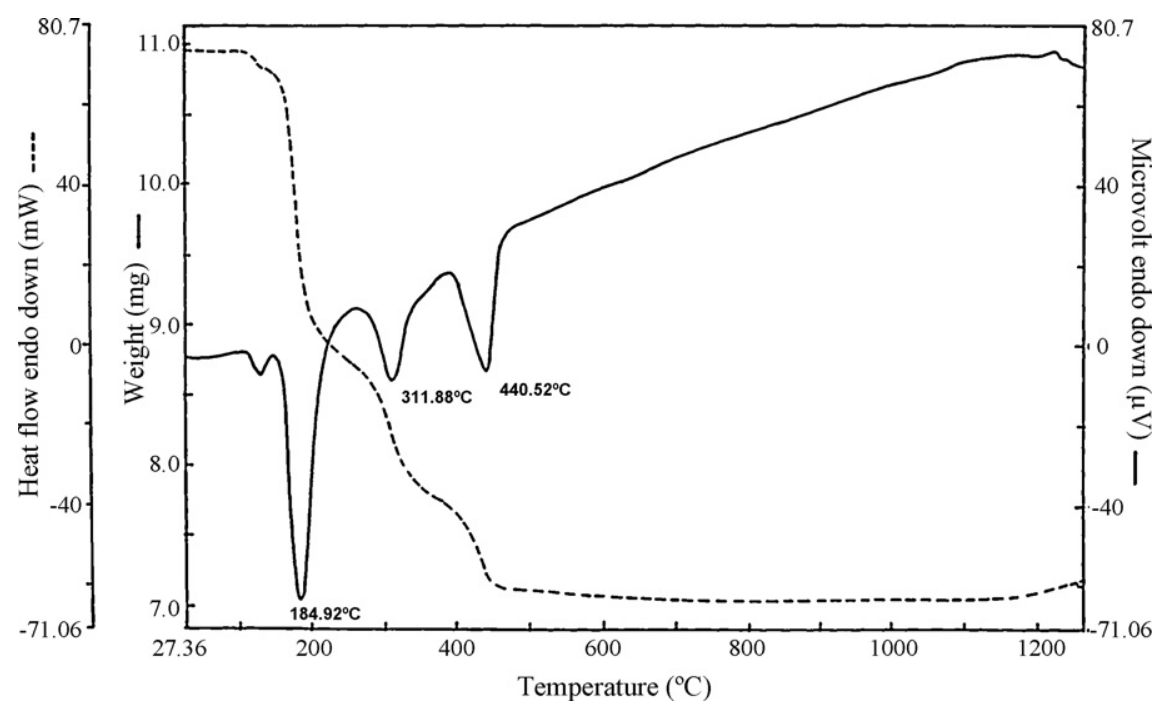

Fig. 7. TG/DTA curve of APB.

The thermal decomposition of APB can be written as below

$$
\begin{aligned}
& \left(\mathrm{NH}_{4}\right)_{2} \mathrm{O} \cdot 5 \mathrm{~B}_{2} \mathrm{O}_{3} \cdot 8 \mathrm{H}_{2} \mathrm{O} \\
& \stackrel{\left(3 \mathrm{H}_{2} \mathrm{O}\right)}{\longrightarrow}\left(\mathrm{NH}_{4}\right) 5 \mathrm{~B}_{2} \mathrm{O}_{3} \cdot 5 \mathrm{H}_{2} \mathrm{O}+3 \mathrm{H}_{2} \mathrm{O}_{(\text {gas })}
\end{aligned}
$$

$\left(\mathrm{NH}_{4}\right)_{2} 5 \mathrm{~B}_{2} \mathrm{O}_{3} \cdot 5 \mathrm{H}_{2} \mathrm{O} \stackrel{\left(2 \mathrm{H}_{2} \mathrm{O}\right)}{\longrightarrow}\left(\mathrm{NH}_{4}\right)_{2} 5 \mathrm{~B}_{2} \mathrm{O}_{3}+2 \mathrm{H}_{2} \mathrm{O}_{(\text {gas })}$

$\left(\mathrm{NH}_{4}\right)_{2} 5 \mathrm{~B}_{2} \mathrm{O}_{3} \cdot \mathrm{H}_{2} \mathrm{O} \stackrel{\left(\mathrm{NH}_{3}\right)}{\longrightarrow} 5 \mathrm{~B}_{2} \mathrm{O}_{3}+\left(\mathrm{NH}_{4}\right)_{(\text {gas })}$

\subsection{Differential scanning calorimetry}

Differential scanning calorimetric study (DSC) was carried out on a PerkinElmer DSC 7 calorimeter with a heating rate of $10^{\circ} \mathrm{C} / \mathrm{min}$ in nitrogen atmosphere. For this a small piece of crystal weighing $8.446 \mathrm{mg}$ was placed in an aluminium pan. The sample was scanned over the temperature range from 25 to $550^{\circ} \mathrm{C}$. The DSC plot [Fig. 8] shows a sharp peak at $174.95^{\circ} \mathrm{C}$.

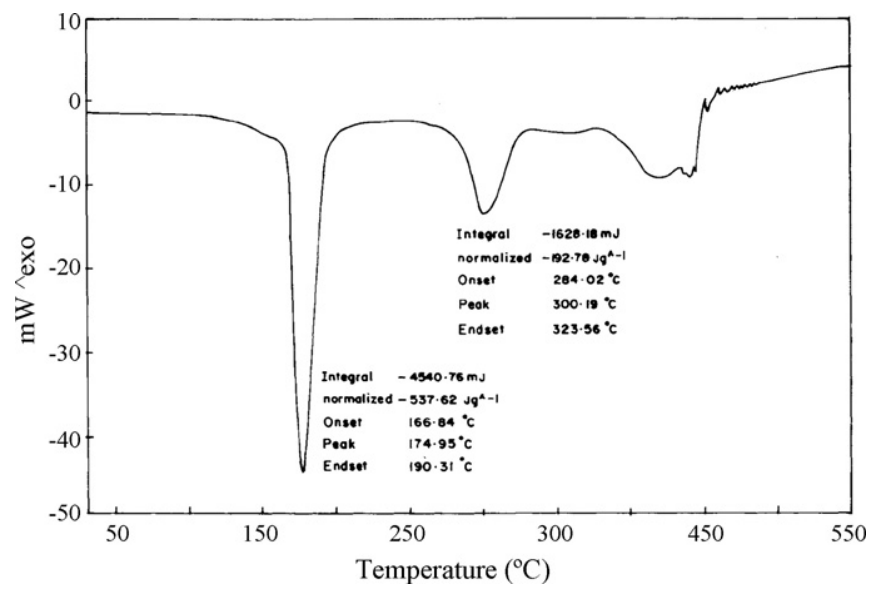

Fig. 8. DSC curve of the APB.
This well marked endothermic peak is due to the melting of the compound.

\subsection{Melting point and density measurements}

Powdered form of APB single crystal was filled in the capillary tube and the capillary tube was placed in the melting point measuring apparatus. The temperature was increased slowly and the melting of the material was observed at $175^{\circ} \mathrm{C}$.

The measurement of density is one of the important parameter to study the purity of the crystal. The flotation technique was used. In the present study bromoform and chloroform were used for the measurements of density of APB crystal. Experimentally determined value $\left(1.56 \mathrm{~g} / \mathrm{cm}^{3}\right)$ is in good agreement with the theoretically found value $\left(1.563 \mathrm{~g} / \mathrm{cm}^{3}\right)$ using the formula $\rho=(M Z) / N V$; where $M$ is the molecular weight, $Z$ is the number of molecules per unit cell, $N$ is the Avogadro number and $V$ is the volume.

\subsection{SHG studies}

Kurtz [12] second harmonic generation (SHG) test was performed to find the NLO property of APB crystal. The powdered crystal was illuminated using Spectra Physics Quanta Ray S2. Nd:YAG laser using the first harmonics output of $1064 \mathrm{~nm}$ with pulse width of $8 \mathrm{~ns}$ and repetition rate $10 \mathrm{~Hz}$. The second harmonics signal, generated in the crystal was confirmed from the emission of green radiation by the crystal. The SHG radiations of $532 \mathrm{~nm}$ green light was collected by a photomultiplier tube (PMT-Philips Photonics-model 8563) after being monochromated (monochromator-model Triax-550) to collect only the $532 \mathrm{~nm}$ radiation. The optical signal incident on the PMT was converted into voltage output at the CRO (TektronixTDS 3052B). The input laser energy incident on the powdered sample was chosen to be $3.4 \mathrm{~mJ}$. The result obtained for APB shows a powder SHG efficiency of about 0.75 times that of KDP crystal. 


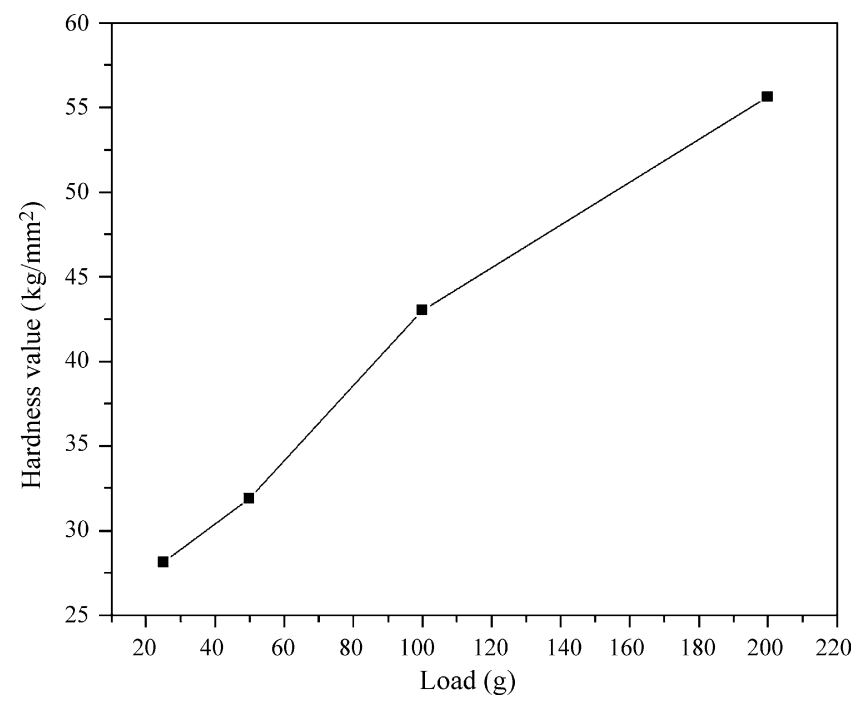

Fig. 9. Hardness behaviour of APB crystal.

\subsection{Microhardness studies}

Vickers microhardness measurements were carried out on APB crystal using microhardness tester fitted with a diamond indentor. The indentations were made using a Vickers pyramidal indentor for various loads from 10 to $200 \mathrm{~g}$. The diagonals of the impressions were measured using Shimadzu (Japan): Model HMV-2 hardness instrument. The measurements were made on the well-developed (10 1) face. Vickers microhardness number $\left(H_{\mathrm{V}}\right)$ was evaluated from the relation. $H_{\mathrm{v}}=1.8544\left(P / d^{2}\right) \mathrm{kg} / \mathrm{mm}^{2}$, where $P$ is the indenter load in $\mathrm{kg}$ and $d$ is the diagonal length of the impression in $\mathrm{mm}$. The variation of microhardness values with applied load is shown in Fig. 9. Hardness values are found to increase with increasing load. For loads above $200 \mathrm{~g}$ crack started developing around the indentation mark which may be due to the release of internal stresses [13].

\section{Conclusion}

Solubility of APB was estimated, which indicates water as a suitable solvent for growing single crystal of this material. Optically transparent, APB crystal with dimension of about $11 \mathrm{~mm} \times 10 \mathrm{~mm} \times 6 \mathrm{~mm}$ was grown by temperature reduction method. Single crystal X-ray diffraction data reveals that the APB belongs to monoclinic system. HRXRD studies reveal that the crystalline perfection of the grown crystals is reasonably good. The effect of nylon thread on the crystalline perfection is elucidated. FT-IR analysis confirms the presence of various functional groups. The lower cut off wavelength $(230 \mathrm{~nm})$ and the transmittance range $(240-1500 \mathrm{~nm})$ observed from the UV-vis-NIR spectrum confirms its suitability for SHG applications. TGA and DTA reveal that this compound is stable up to about $165^{\circ} \mathrm{C}$. The Vicker's hardness values increases with increasing load and the crystal experiences cracks for loads above $200 \mathrm{~g}$. Powder SHG efficiency of APB observed is about 0.75 times that of KDP.

\section{Acknowledgements}

One of the authors (TB) is grateful to the University Grants Commission for the award of Research Fellowship under the Faculty Improvement Programme (FIP). The authors acknowledge Prof. P.K. Das, Department of Inorganic and Physical Chemistry, Indian Institute of Science, Bangalore for having extended the laser facilities for the SHG measurement.

\section{References}

[1] O. Sahin, N. Genli, M. Ozdemir, J. Cryst. Growth 253 (2003) 488495.

[2] W.R. Cook Jr., H. Jaffe, Acta crystallogr. 10 (1957) 705.

[3] Md. Shabuddin Khan, T.S. Narasimhamurthy, Y.V. Ramana, J. Mater. Sci. 2 (1983) 629-633.

[4] Md. Shabuddin Khan, T.S. Narasimhamurthy, J. Mater. Sci. 19 (1984) $1787-1790$

[5] X. Solans, M. Font Altaba, M. Aguilo, J. Solans, M.V. Domenech, J. Appl. Cryst. 16 (1983) 637-640.

[6] A.C. Zettlemoyer, Nucleation, New York (1969) 243.

[7] Krishan Lal, G. Bhagavannarayana, J. Appl. Cryst. 22 (1989) 209-215.

[8] B.W. Betterman, H. Cole, Rev. Mod. Phys. 36 (1964) 681-717.

[9] G. Bhagavannarayana, A. Choubey, Y.V. Shubin, K. Lal, J. Appl. Cryst. 38 (2005) 448-454.

[10] V. Joseph, S. Gunasekaran, V. Santhanam, Bull. Mater. Sci. 26 (2003) 383-386.

[11] O. Sahin, M.O. Mehmir, M. Aslanoglu, G. Beker, Ind. Eng. Chem. Res. 40 (2001) 1465-1470.

[12] S.K. Kurtz, T.T. Perry, J. Appl. Phys. 39 (1968) 3798-3813.

[13] P.M. Ushasree, R. Jayavel, C. Subramanian, P. Ramasamy, Bull. Electrochem. 14 (1998) 407 